\title{
Public Knowledge of Oral Cancer and Modelling of Demographic Background Factors Affecting this Knowledge in Khartoum State, Sudan
}

"Hamdi A. Al-Hakimi, ${ }^{1}$ Abdulqaher E. Othman, ${ }^{2}$ Omima G. Mohamed, ${ }^{3}$ Abdulaal M. Saied, ${ }^{2}$ Waled A. Ahmed

$$
\text { معرفة العامة من الناس عن سرطان الفم و صياغة العوامل الديموغرافية المؤثرة على المَه المعرفة في ولاية الخرطوم، السودان }
$$

حمدي عبدالوهاب الحكيمي، عبدالقاهر إسماعيل عثمان، أميمة جاداله محمد، عبدالعال سعيد، وليد أمين أحمد

ABSTRACT: Objectives: Knowledge of oral cancer affects early detection and diagnosis of this disease. This study aimed to assess the current level of public knowledge of oral cancer in Khartoum State, Sudan, and examine how demographic background factors affect this knowledge. Methods: This cross-sectional study involved 501 participants recruited by systematic random sampling from the outpatient records of three major hospitals in Khartoum State between November 2012 and February 2013. A pretested structured questionnaire was designed to measure knowledge levels. A logistic regression model was utilised with demographic background variables as independent variables and knowledge of oral cancer as the dependent variable. A path analysis was conducted to build a structural model. Results: Of the 501 participants, 42.5\% had no knowledge of oral cancer, while 5.4\%, 39.9\% and $12.2 \%$ had low, moderate and high knowledge levels, respectively. Logistic regression modelling showed that age, place of residence and education levels were significantly associated with knowledge levels $(P=0.009,0.017$ and $<0.001$, respectively). According to the structural model, age and place of residence had a prominent direct effect on knowledge, while age and residence also had a prominent indirect effect mediated through education levels. Conclusion: Education levels had the most prominent positive effect on knowledge of oral cancer among outpatients at major hospitals in Khartoum State. Moreover, education levels were found to mediate the effect of other background variables.

Keywords: Oral Cancer; Knowledge; Logistic Regression; Statistical Model; Patient-Specific Modeling; Sudan.

الملخص: أهداف: المعرفة عن سرطان الفم تؤثر على الإكتشاف و التشخيص المبكر لهذا المرض، تهدف هذه الدراسة إلى تقييم مستيم مستوى

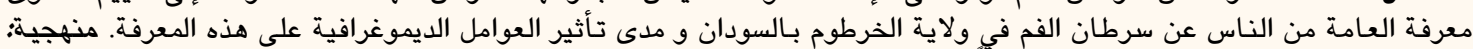

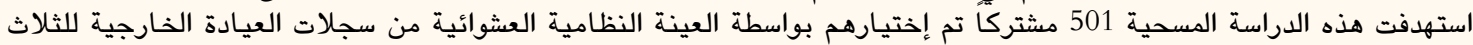

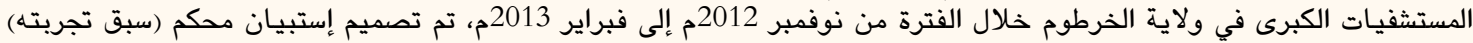

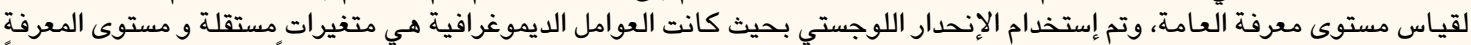

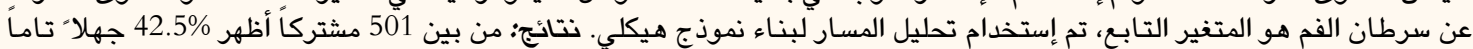

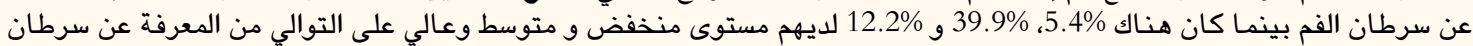

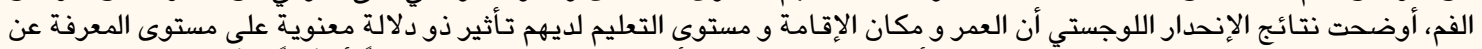

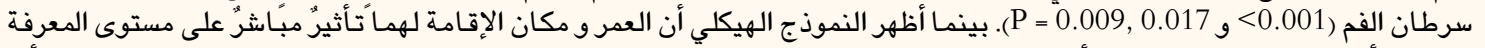

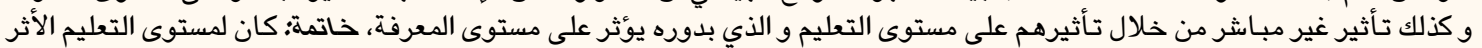

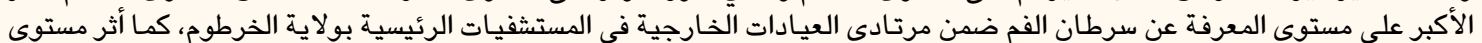

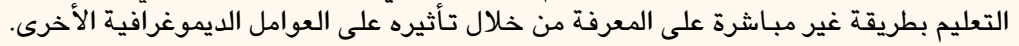

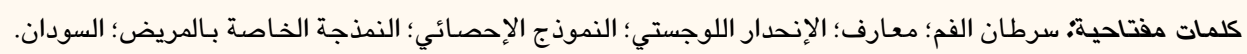

\section{AdvanCes IN KNOWLedge}

Few studies have used advanced statistical techniques to examine the effects of different variables on public knowledge of oral cancer.

To the best of the authors' knowledge, this is the first study to use path analysis to build an explanatory model to examine the effect of demographic background factors on public knowledge of oral cancer.

In the current study, education level was found to prominently affect knowledge of oral cancer in a structural model. This model could potentially be used as a basis for models of other diseases.

\section{application to Patient Care}

The results of this study may help public health practitioners in Sudan to identify which population groups should be targeted for oral cancer prevention and control programmes. 
$\mathrm{T}$ HERE IS WIDE GEOGRAPHICAL VARIATION in the incidence of oral cancer $(\mathrm{OC}) .{ }^{1}$ It is a common cancer in developing countries, particularly Brazil and countries in Southeast Asia. ${ }^{2}$ There is a good chance of survival with early diagnosis and among those who receive necessary treatment. ${ }^{3}$ Despite this, public awareness of $\mathrm{OC}$ is low, which contributes to delays in diagnosis. ${ }^{4-6}$ In Sudan, OC was one of the 10 most common cancers from 1967-1984; however, in recent years it has begun to occur less frequently. ${ }^{7}$ Unfortunately, the majority of patients only seek healthcare during advanced stages of $\mathrm{OC}$, leading to a relatively low five-year survival rate.

Enhanced public knowledge of OC can improve the early detection and self-identification of precancerous lesions. ${ }^{6,8}$ Certain countries, such as India, have conducted mass media campaigns as a prevention strategy, aiming to increase public knowledge of OC. ${ }^{9}$ In a prospective study conducted in India, Gupta et al. observed decreased tobacco use and a lower incidence of leukoplakia among participants of educational programmes regarding risk factors for OC. ${ }^{10}$ However, assessment of the baseline level of public knowledge of $\mathrm{OC}$ is essential for evaluating the effectiveness of such campaigns. In addition, understanding how factors such as age, gender, place of residence and education levels affect knowledge of $\mathrm{OC}$ may help improve public health programmes. This study aimed to assess the current level of public knowledge of OC in Khartoum State, Sudan, and examine how demographic background factors affect this knowledge.

\section{Methods}

This cross-sectional study involved participants recruited from the outpatient clinics of three major hospitals in Khartoum State between November 2012 and February 2013. An appropriate sample size was calculated according to the following equation:

$$
n=\frac{z^{2} p q}{d^{2}}
$$

where $\mathrm{p}$ represents the percentage of those who are aware of OC, set at $50 \%$ since no data were available from Sudan and to yield the largest possible sample size. As a result, the minimum sample size was calculated to be 384 participants. This was increased to 500 because modelling usually requires a large sample size, with 50 subjects necessary for each variable. Accordingly, a total of 501 participants were included. Participants were selected by systematic random sampling from the outpatient records of the Khartoum Teaching Hospital $(\mathrm{n}=300)$, Omdurman General Hospital $(\mathrm{n}=100)$ and Bahri General Hospital $(n=101)$. Khartoum Teaching Hospital is the largest hospital in Sudan and usually receives triple the number of patients of the other two hospitals; therefore, the number of study subjects selected from this hospital was three times higher than that of the other hospitals.

An Arabic-language 23-item pre-tested structured questionnaire was designed to assess the participants' knowledge of OC. During face-to-face interviews, questions were explained to the study participants and answers recorded. The first five items of the questionnaire focused on demographic background variables, while item 6 determined whether patients had heard of OC. Subsequently, items 7-14 determined awareness of risk factors, items 15-18 awareness of the symptoms of OC and items 19-23 knowledge of treatments for and outcomes of OC. For all items except items 1-6 and 22, a score of 1 was given for correct answers, 0.5 when participants indicated that they did not know the answer and zero for incorrect responses, allowing for a maximum score of $16 .{ }^{11}$ For item 22 , scores ranged from $1-3$, as this question was multiple choice with three possible correct answers. Therefore, a total of 17 questions evaluated knowledge of OC among those who indicated that they had heard of OC. Scores were added to obtain a total knowledge score for each participant ranging from 0-19. Scores of $<9.5$ (below the median) were considered to indicate a low level of knowledge, scores of 9.5-14.5 to indicate a moderate level of knowledge (representing the third quartile of data) and scores $>14.5$ to indicate a high level of knowledge (representing the upper quartile). The internal consistency of the questionnaire was assessed using Cronbach's alpha test. Subsequently, certain items of the questionnaire were modified in order to obtain a Cronbach's alpha score of $\geq 71 \%$.

Data were analysed using the Statistical Package for the Social Sciences (SPSS), Version 20 (IBM Corp., Chicago, Illinois, USA) to provide descriptive statistics and conduct the logistic regression modelling. For the latter analysis, participants were divided into two groups - those with no or low knowledge versus those with moderate or high knowledge. Demographic background variables (e.g. gender, age, education level and place of residence) were introduced into the logistic regression model as independent variables, with knowledge level as the dependent variable. Logistic regression assesses the association between an independent variable and the dependent variable while adjusting for the confounding effect of other independent variables. However, this can be a disadvantage if some independent variables have a mediating effect on other variables. ${ }^{12}$ Using regression analysis to adjust for the effect of a mediating variable can yield incorrect estimations 
Table 1: Demographic background variables of outpatients at three major hospitals in Khartoum State, Sudan $(\mathrm{N}=501)$

\begin{tabular}{lc} 
Variable & $\mathbf{n}(\%)$ \\
Gender & \\
Male & $257(51)$ \\
Female & $244(49)$ \\
Place of residence & \\
Urban & $327(65)$ \\
Rural & $174(35)$ \\
Age in years & \\
$18-30$ & $247(49.3)$ \\
$31-40$ & $106(21.2)$ \\
$41-50$ & $80(16.0)$ \\
$51-60$ & $41(8.2)$ \\
$>60$ & $27(5.4)$ \\
Education level & \\
Illiterate & $115(23.0)$ \\
Primary & $141(28.1)$ \\
Secondary & $112(22.4)$ \\
University & $133(26.5)$ \\
Employment status & $104(21.0)$ \\
Student & $143(29.0)$ \\
Housewife & $67(13.0)$ \\
Unskilled worker & \\
Private or public sector employee & \\
\hline
\end{tabular}

for a studied association. ${ }^{12}$ Path analysis is the logical extension of multiple regression models as it can correctly estimate the shape and strength of relations between independent variables, mediators and dependent variables. ${ }^{13}$ Therefore, path analysis using LISREL software, Version 8.51 (Scientific Software International Inc., Skokie, Illinois, USA) was subsequently performed to analyse and estimate the relationships between background variables and knowledge of OC. Specification of the structural model was undertaken by assuming that the independent variables could have a direct effect on knowledge as a dependent variable or an indirect effect mediated by another variable. The identification step was conducted by satisfying the necessary condition where the number of free estimated parameters should be equal to or less than the number of distinct values.
Table 2: Levels of oral cancer knowledge among outpatients at three major hospitals in Khartoum State, Sudan $(\mathrm{N}=501)$

$\begin{array}{lc}\text { Level of knowledge } & \mathbf{n}(\%) \\ \text { None } & 213(42.5) \\ \text { Low } & 27(5.4) \\ \text { Moderate } & 200(39.9) \\ \text { High } & 61(12.2)\end{array}$

Table 3: Levels of knowledge of risk factors, symptoms, treatment options and outcomes of oral cancer among

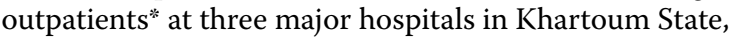
Sudan $(\mathrm{N}=288)$

$\begin{array}{lccc}\begin{array}{l}\text { Level of } \\ \text { knowledge }\end{array} & \begin{array}{c}\text { Risk } \\ \text { factors }\end{array} & \text { Symptoms } & \begin{array}{c}\text { Treatment } \\ \text { options and } \\ \text { outcomes }\end{array} \\ \text { Low } & 79(27.4) & 88(30.6) & 103(35.8) \\ \text { Moderate } & 170(59.0) & 85(29.5) & 155(53.8) \\ \text { High } & 39(13.5) & 115(39.9) & 30(10.4) \\ \text { *Including only those individuals who had previously heard of oral cancer. }\end{array}$

The number of free parameters was obtained from the following equation:

$$
\rho \times \frac{\rho+1}{2}
$$

where $\rho$ is the number of variables. As the number of variables was five, the number of free parameters was 15. In the structural model, the number of estimated free parameters was 12 . Thus, the necessary condition showed that the model was over-identified, which is acceptable. ${ }^{14}$ The estimates were standardised to allow for comparisons among variables of different scales.

Ethical approval for this study was granted by the Sudan Medical Specialization Board in Khartoum. Written consent from literate subjects and witnessed verbal consent from illiterate subjects was obtained after the objectives of the study were explained and confidentiality assured.

\section{Results}

The demographic characteristic of the participants are shown in Table 1. A total of 288 participants (57.5\%; confidence interval [CI]: 53-61\%) had previously heard of OC. Overall, $42.5 \%$ had no knowledge of OC, 5.4\% had a low level of knowledge, 39.9\% had a moderate level of knowledge and $12.2 \%$ had a high level of knowledge [Table 2]. There were apparent background similarities between those who had no or low knowledge and those who had moderate or high knowledge. Table 3 presents the knowledge levels of 
Table 4: Logistic regression modelling of demographic background variables with knowledge of oral cancer among outpatients at three major hospitals in Khartoum State, Sudan $(\mathrm{N}=501)$

$\begin{array}{lcc}\text { Variable } & \text { OR }(\text { CI }) & P \text { value } \\ \text { Age } & 1.02(1.01-1.04) & 0.009 \\ \text { Urban residence* }^{*} & 1.64(1.10-2.46) & 0.017 \\ \text { Primary education }^{\dagger} & 4.30(2.40-7.71) & <0.001 \\ \text { Secondary education }^{\dagger} & 9.26(4.84-17.71) & <0.001 \\ \text { University education }^{\dagger} & 14.24(7.30-27.76) & <0.001\end{array}$

$O R=$ odds ratio; $C I=$ confidence interval.

*Reference group include those living in a rural residence. ${ }^{\dagger}$ Reference group include those who were illiterate.

OC risk factors, symptoms, treatment options and outcomes among those who had previously heard of OC. Table 4 shows the results of logistic regression modelling. Age, urban residence and education level were significantly associated with knowledge levels $(P=0.009,0.017$ and $<0.001$, respectively).

As gender did not significantly contribute to the logistic regression model, it was excluded. A best-fit model was selected to show the effect of background variables on knowledge levels. The effect of education levels on knowledge of OC was significant. When the education level increased from illiterate to primary school, knowledge levels increased fourfold; when education level increased from illiterate to secondary school, knowledge levels increased nine-fold; and when education levels increased from illiterate to university level, knowledge levels increased fourteen-fold. Additionally, levels of knowledge increased slightly with age. Finally, living in an urban area resulted in a one-and-a-half-fold increase in knowledge levels in comparison to living in a rural area.

The path analysis structural model is shown in Figure 1 . In the path analysis, it was assumed logically

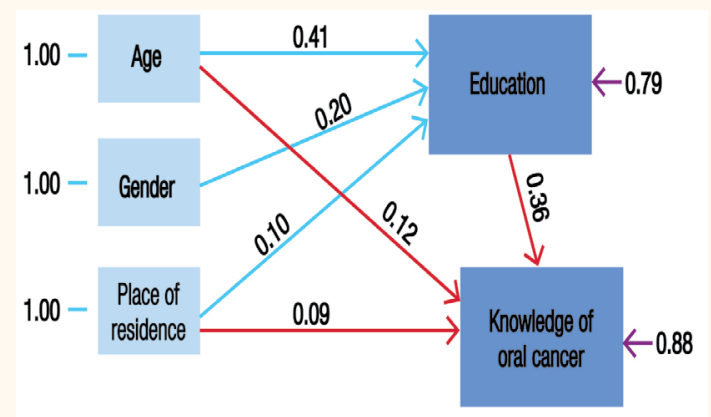

\section{$\chi^{2}=0.52 ; d f=3 ; P=0.915 ;$ RMS error of approximation $=0.000$}

Figure 1: Path analysis structural model of the effect of background variables on knowledge of oral cancer among outpatients at three major hospitals in Khartoum State, Sudan $(\mathrm{N}=501)$.

$d f=$ degrees of freedom; $R M S=$ root-mean-square.
Table 5: Fitness measures of a path analysis structural model for demographic background variables and knowledge of oral cancer among outpatients at three major hospitals in Khartoum State, Sudan $(\mathrm{N}=501)$

\begin{tabular}{|c|c|c|}
\hline Measure & Acceptable level & $\begin{array}{c}\text { Current } \\
\text { model }\end{array}$ \\
\hline Chi-squared test & Non-significant $P$ value & $P=0.915$ \\
\hline GF index & 0 (no fit) to 1 (perfect fit) & 1 \\
\hline Adjusted GF index & 0 (no fit) to 1 (perfect fit) & 0.998 \\
\hline RMS residual & Researcher-defined & 0.0026 \\
\hline $\begin{array}{l}\text { RMS error of } \\
\text { approximation }\end{array}$ & $<0.080$ & 0.000 \\
\hline NF index & 0 (no fit) to 1 (perfect fit) & 0.997 \\
\hline
\end{tabular}

$G F=$ goodness-of-fit $; A G F I=$ adjusted $G F$ index $; R M S=$ root-mean square $N F=$ normed fit.

that education levels would mediate the effect of other background variables on knowledge levels. According to the structural model, age and place of residence had a prominent direct effect on knowledge, while age and residence also had a prominent indirect effect mediated through education level. Education level had the largest positive effect on OC knowledge $(r=0.36)$ followed by age, which had a slightly weaker positive effect $(r=0.12)$. On the other hand, age had a moderately negative effect on education level $(r=-0.41)$ while urban residence had a weak positive effect on OC knowledge ( $r=0.09)$. In addition, urban residence had a weak positive effect on education level $(r=0.10)$. Measures testing the fitness of the model are presented in Table 5. The structural model was an almost perfect fit according to a Chi-squared goodnessof-fit test $\left(X^{2}=0.52 ; P=0.915\right)$, where a non-significant value means that the model fits the data. The model did not need any modification, thereby indicating good specification of variables and relationships.

\section{Discussion}

This study aimed to assess current levels of public knowledge of OC in Khartoum State and examine how demographic background factors affected knowledge levels. In terms of background variables, the study sample was quite similar to that of the general population living in Khartoum State. ${ }^{15}$ Furthermore, there were apparent background similarities between those who had no or low knowledge and those who had moderate or high knowledge; this supports the grouping of these participants together during the logistic regression analysis.

In the current study, knowledge of OC was significantly affected by age, residence and, in particular, education levels. This latter association has been observed in many studies..$^{911,16,17}$ The present 
study included participants with wide variability in educational backgrounds and found that education level prominently affected OC knowledge; in contrast, research focusing on homogenous populations might fail to detect this association. For example, Comunian et al. found that the association between education and OC knowledge levels was not statistically significant; however, the study investigated a population with a high base level of education-professors, students and administrative staff at a university. ${ }^{18}$ Knowledge of OC was also affected by place of residence in the current study, with urban participants found to be more knowledgeable than their rural counterparts. Agrawal et al. have reported similar findings. ${ }^{17}$ However, Amarasinghe et al. found that residents of rural villages in Sri Lanka had higher levels of OC knowledge than residents of urban tea estates. ${ }^{19}$ Socioeconomic status can affect access to information, so this finding could be due to the lower socioeconomic status of the estate residents in comparison to the villagers. Moreover, the majority of villagers reported receiving information regarding $\mathrm{OC}$ from the mass media, whereas estate residents reported receiving information from family members. ${ }^{19}$ Information received from the media generally could be considered more accurate than information gathered from family members in less socioeconomically developed communities.

Additionally, knowledge of $\mathrm{OC}$ was affected by age in the current study, which is a similar finding to those reported by previous studies., ${ }^{9,16,17,20,21}$ Generally, studies from different countries have shown a nonlinear association between age and knowledge of $\mathrm{OC}$, where knowledge of $\mathrm{OC}$ increases with age until patients are 60-65 years old, at which point knowledge of OC begins to decline. ${ }^{16,20,21}$ Some studies from India have shown higher knowledge of $\mathrm{OC}$ in younger age groups., ${ }^{917}$ Increased awareness among individuals of younger age groups in India can be attributed to wide media exposure of $\mathrm{OC}$ and various anti-tobacco campaigns conducted in recent years. ${ }^{9,17}$ On the other hand, other research has indicated that knowledge of OC is unaffected by age. ${ }^{4,19}$ This variation in findings may be due to methodological flaws, which can decrease the statistical power of a study to detect a significant effect. Rogers et al. found that age had no effect on knowledge of $\mathrm{OC}$ in general, but significantly affected certain important OC risk factors, like smoking. ${ }^{4}$ In the study conducted by Amarasinghe et al., although a robust methodology was used, the researchers included only participants aged over 30 years old, which may have reduced detection of the effect of age on knowledge of OC. ${ }^{19}$

Finally, the current study found that knowledge of OC was unaffected by gender, which is similar to findings from the international literature.,16-19,21-23
Nevertheless, a few studies have found a significant association between gender and knowledge of OC..$^{20,24}$ However, Oh et al. reported that the effect of gender on knowledge levels was minor, as they found that males were only slightly more knowledgeable than females (odds ratio $=1.2$ ). ${ }^{20}$ Rogers et al. and Al-Rawi et al. conducted surveys with convenience samples and found that females had statistically significant greater knowledge than males using a Chi-squared test.,24 However, the use of statistical tests is questionable in surveys with convenience or non-random samples, as differences could be the result of sampling bias.

The path analysis structural model from the current study demonstrated excellent specification and goodness-of-fit, as shown by fitness measures. The model showed that age and place of residence had a prominent direct effect on knowledge of OC and a prominent indirect effect mediated through education level. The purpose of path analysis in the present study was to avoid the incorrect estimation of associations during regression analysis; in this structural model, estimates were produced using the full information method where all other associations were taken into consideration during calculation. Education level was found to have the largest positive effect on OC knowledge, followed by age. However, age had a moderately negative effect on education level. The latter finding is to be expected as, in Sudan, individuals of younger age groups are more educated than their elders. ${ }^{15}$ This direct and indirect effect of age on $\mathrm{OC}$ knowledge may explain why certain studies from India have found a negative effect of age on OC knowledge; ${ }^{9,17}$ while the direct positive effect of age on $\mathrm{OC}$ knowledge might be low, the indirect negative effect mediated by education level might be much higher. Urban residence was also found to increase OC knowledge in the current study; however, it had a weak positive effect. In addition, education levels were weakly positively affected by urban residence; this makes sense as urban residents are more educated than their rural counterparts in Sudan..$^{15}$ Gender was found to affect knowledge of OC indirectly; this may be because of its effect on education level, as males have greater access to education than females in many developing countries. ${ }^{25}$

Based on the findings from this study, public health programmes in Khartoum State which aim to improve knowledge of OC should focus on non-educated persons and those from rural areas. Educational strategies should be designed to benefit these individuals, since current strategies seem to target educated people and those living in urban areas. Education plays a fundamental role in any long-term strategy aiming to improve public knowledge and awareness of OC. The structural model designed in 
the current study may potentially be used in other developing countries which have populations with a similar demographic structure and background variables. However, this study is limited by its crosssectional design, as generally a longitudinal design is more appropriate for model development. Additionally, this study did not utilise a standardised questionnaire with predetermined reliability and validity to determine OC knowledge; however, Cronbach's alpha test was used to ensure internal consistency.

\section{Conclusion}

Approximately half of the Sudanese outpatients in the current study had never heard of OC. Furthermore, among those who had heard of $\mathrm{OC}$, the majority only had a moderate level of knowledge of the disease. Education level was found to have the most prominent positive effect on knowledge of OC. Moreover, education level was found to mediate the effect of other background variables.

\section{CONFLICT OF INTEREST}

The authors declare no conflicts of interest.

\section{FUNDING}

No funding was received for this study.

\section{ACKNOWLEDGEMENTS}

The authors wish to thank the authorities of the Khartoum Teaching Hospital, Omdurman General Hospital and Bahri General Hospital for their cooperation during the data collection process.

\section{References}

1. Warnakulasuriya S. Global epidemiology of oral and oropharyngeal cancer. Oral Oncol 2009; 45:309-16. doi: 10.1016/j.oraloncology.2008.06.002.

2. Scully C, Porter S. ABC of oral health: Oral cancer. BMJ 2000; 321:97-100. doi: 10.1136/bmi.321.7253.97.

3. Sankaranarayanan R, Ramadas K, Thomas G, Muwonge R, Thara S, Mathew B, et al. Effect of screening on oral cancer mortality in Kerala, India: A cluster-randomised controlled trial. Lancet 2005; 365:1927-33. doi: 10.1016/S0140-6736 (05)66658-5

4. Rogers S, Pabla R, McSorley A, Lowe D, Brown JS, Vaughan ED. An assessment of deprivation as a factor in the delays in presentation, diagnosis and treatment in patients with oral and oropharyngeal squamous cell carcinoma. Oral Oncol 2007; 43:648-55. doi: 10.1016/j.oraloncology.2006.08.001.

5. Zakrzewska JM. Fortnightly review: Oral cancer. BMJ 1999; 318:1051-4. doi: 10.1136/bmj.318.7190.1051.

6. Seoane-Romero JM, Vázquez-Mahía I, Seoane J, VarelaCentelles P, Tomás I, López-Cedrún JL. Factors related to late stage diagnosis of oral squamous cell carcinoma. Med Oral Patol Oral Cir Bucal 2012; 17:e35-40. doi: 10.4317/medoral.17399.
7. Hamad HM. Cancer initiatives in Sudan. Ann Oncol 2006; 17:viii32-viii36. doi: 10.1093/annonc/mdl985.

8. van der Waal I. Are we able to reduce the mortality and morbidity of oral cancer: Some considerations. Med Oral Patol Oral Cir Bucal 2013; 18:e33-7. doi: 10.4317/medoral.18486.

9. Devadiga A, Prasad KV. Knowledge about oral cancer in adults attending a dental hospital in India. Asian Pac J Cancer Prev 2010; 11:1609-13.

10. Gupta PC, Mehta FS, Pindborg JJ, Bhonsle RB, Murti PR, Daftary DK, et al. Primary prevention trial of oral cancer in India: A 10-year follow-up study. J Oral Pathol Med 1992; 21:433-9. doi: 10.1111/j.1600-0714.1992.tb00970.x.

11. Shirzaiy M, Dalirsani Z, Pakfetrat A. Oral cancer awareness of people attending the Oral Medicine Center of Zahedan Dental School. Aust J Basic Appl Sci 2011; 5:984-9.

12. Amorim LD, Fiaccone RL, Santos CA, Santos TN, Moraes LT, Oliveira NF, et al. Structural equation modeling in epidemiology. Cad Saude Publica 2010; 26:2251-62. doi: 10.1590/ S0102-311X2010001200004.

13. Baker SR, Gibson BG. Social oral epidemi(olog)(2) y where next: One small step or one giant leap? Community Dent Oral Epidemiol 2014; 42:481-94. doi: 10.1111/cdoe.12118.

14. Schumacker RE, Lomax RG. A Beginner's Guide to Structural Equation Modelling, 3rd ed. Mahwah, New Jersey, USA: Routledge, 2010. P. 214

15. Sudan Central Bureau of Statistics. Sudan National Baseline Household Survey 2009: North Sudan - tabulation report. From: http://ecastats.uneca.org/aicmd/Portals/1/Publications/ Others/POVERTY\%202009.pdf Accessed: Apr 2016.

16. Tomar SL, Logan HL. Florida adults' oral cancer knowledge and examination experiences. J Public Health Dent 2005; 65:221-30. doi: 10.1111/j.1752-7325.2005.tb03022.x

17. Agrawal M, Pandey S, Jain S, Maitin S. Oral cancer awareness of the general public in Gorakhpur city, India. Asian Pac J Cancer Prev 2012; 13:5195-9. doi: 10.7314/APJCP.2012.13.10.5195.

18. Comunian CR, Abdo EN, Mendonça LL, Naves MD. Basic knowledge on oral cancer among a specific Brazilian population. Odontol Clín Cient 2011; 10:351-6.

19. Amarasinghe HK, Usgodaarachchi US, Johnson NW, Lalloo R, Warnakulasuriya S. Public awareness of oral cancer, of oral potentially malignant disorders and of their risk factors in some rural populations in Sri Lanka. Community Dent Oral Epidemiol 2010; 38:540-8. doi: 10.1111/j.1600-0528.2010.00566.x.

20. Oh J, Kumar J, Cruz G. Racial and ethnic disparity in oral cancer awareness and examination: 2003 New York State BRFSS. J Public Health Dent 2008; 68:30-8. doi: 10.1111/j.17527325.2007.00075.x.

21. Patton LL, Agans R, Elter JR, Southerland JH, Strauss RP, Kalsbeek WD. Oral cancer knowledge and examination experiences among North Carolina adults. J Public Health Dent 2004; 64:173-80. doi: 10.1111/j.1752-7325.2004.tb02748.x.

22. Ariyawardana A, Vithanaarachchi N. Awareness of oral cancer and precancer among patients attending a hospital in Sri Lanka. Asian Pac J Cancer Prev 2005; 6:58-61.

23. Monteiro LS, Salazar F, Pacheco J, Warnakulasuriya S. Oral cancer awareness and knowledge in the city of Valongo, Portugal. Int J Dent 2012; 2012:376838. doi: 10.1155/2012/376838.

24. Al-Rawi NH, Al-Kawas S, Imad O. Public awareness and attitude toward oral cancer screening in the United Arab Emirates. J Int Dent Med Res 2012; 5:149-54.

25. King EM, Hill MA. Women's education in developing countries: Barriers, benefits, and policies. Washington D.C., USA: World Bank Publications, 1997. Pp. 7-10. 